\title{
Adaptive PI Controllers for Doubly Fed Induction Generator using B-spline Artificial Neural Networks
}

\author{
Rubén Tapia-O. and Omar Aguilar M. \\ Electrical Engineering Department, Polytechnic \\ University of Tulancingo, Tulancingo, Hidalgo, \\ Mexico
}

\author{
Abel García-B. and Omar J. Santos-S. \\ Research Center for Information Technologies and \\ Systems, Autonomous University of Hidalgo State \\ (UAEH), Hidalgo, Mexico
}

\begin{abstract}
This paper presents the design and simulation of adaptive PI controllers for doubly fed induction generators using b-spline neural networks. The control structure is based on a back-toback arrangement where the interest variables are regulated by PI linear controllers. Also, to deal with the nonlinear and uncertain system conditions, we proposed that the control parameters are updated online. The main task is that the power converters operation adapt by itself during the grid changes. Then, the basic problem consists of tuning the PI controllers simultaneously when the system and load are subjected to disturbances. The applicability of the proposal is demonstrated by simulation in a three-node grid, where one end is an infinite bus and the other connects the wind system, between them there are two transmission lines. The results show that the proposed controllers' tuning is comparable to that obtained by a conventional design, without requiring of a detailed model, which enable optimal speed tracking for maximum energy capture from the wind.
\end{abstract}

\section{Keywords}

Adaptive PI Controllers, B-spline Artificial Neural Network, Induction Generators.

\section{INTRODUCTION}

Now days, electric grids have limitations of power flows transfer from conventional generation plants to electricity consumers because the system could operate at the stability limits. However, with the technology advanced in power electronic devices is possible to include several generation systems based on alternative sources near to loads. However, an important part of the successful depends on power electronic devices control. Electrical power generation with wind and solar as power sources may be considered of the most promising renewable energy sources, but the control schemes are important issues [1]. There are extensive frameworks of various electrical machines types and controls algorithms that have been developed for wind generator applications [2-3]. Among the schemes of wind energy conversion systems (WECS), the induction and permanent magnet synchronous machines are seen as promising elements for energy conversion. In all cases back to back (BTB) arrangement based on power electronics is required to get benefits [3-5]. BTB structure is formed by two identical voltage source converters (VSC) connected by a common dclink. This topology presents several advantages in terms of power processing and allows bidirectional power flow with quasi-sinusoidal currents. The load can be active, passive or even another network, in such case achieve a unity power factor is possible if it is required. The dc-link in the middle provides decoupling between both converters; as a result, they could be driven independently. Therefore, it is possible to have a fast and independent control of active and reactive power for both converters and improve the system operation [6]. To attain simultaneously these benefits is important to explore control strategies, which allow obtaining the desired regulation. Several studies that examine WECS have been developed and make different proposals about what should be the control scheme and the tuning methodology [4-5, 7-8]. The ref. [1] presents a review of numerous control strategies adapted for WECS application, thus establishing that there is great interest in getting a better algorithm for secure and reliable system operation. Some of them considered PI controllers for control schemes in BTB converters $[4,9]$. The linear models design can exhibit some deficiencies for instance the controller tuning is guaranteed around an equilibrium point, when the system is subjected to changes in its operating condition or structure the performance is diminished. There are also several proposed adaptive controls to determine the controllers $[8,10]$. In the ref. [10] adaptive PID gains for each controller to achieve satisfactory performance is proposed. The use of neural networks to model chaotic systems and nonlinear identification problems has attracted considerable attention in recent years [20]. Neural networks are originally inspired by the functionality of biological neural networks, which can learn complex functional relations based on a limited number of training data. Neural networks can serve as black box models of nonlinear dynamic systems and can be trained using process data coming from the system. The usual neural network consists of multiple simple processing elements, called neurons, the interconnections among them, and the weights attributed to these interconnections. The relevant information of this methodology is stored in the weights. A B-spline neural network (BSNN) consists of the piecewise polynomials with a set of local basis functions to model an unknown function for which a finite set of process samples are available. The performance of the identification depends on an optimization algorithm for the training of the BSNN in order to avoid any possible local minima. The main advantage of the B-spline functions over other radial functions e.g., the Bezier curve, is the local control of the curve shape, since the curve only changes in the vicinity of a few control points that have been changed [19].

In this paper a B-spline neural network (BSNN) is employed for two main tasks: one for PI simultaneous tuning, taking care of a key feature: the proposed controller must be able to enhance the system performance; the second the online parameters updated can be possible. The strategy is proposed to update conventional PI parameters for currently operating in power converters that were tuned time ago. The main idea is to re-tune basically the control gains through an on-line procedure.

\section{MODEL}

There is great interest that alternative generation systems should be included in conventional electrical grids, however, it is also true that further studies are required to fully justifying the feasibility and reliability of new source 


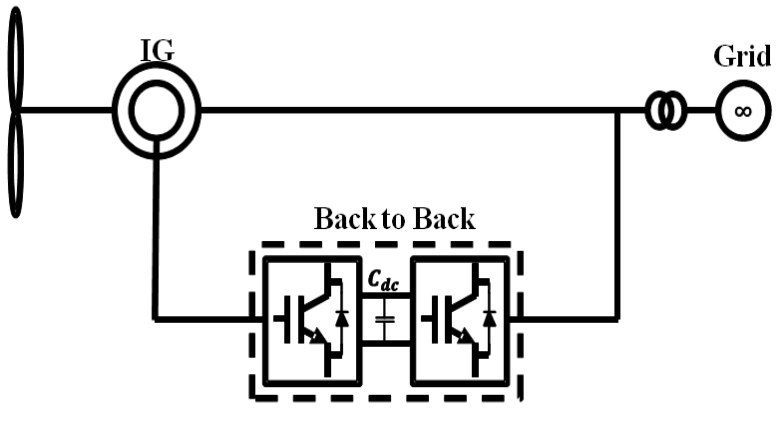

Fig. 1. Wind energy conversion systems (WECS) based on DFIG.

structures. From a design point of view one of the main issues is seeking for a safe and reliable operation under transient and steady state conditions. Therefore, before the implementation a comprehensive analysis using simulation is required, this allows determining system performance. Thus, it is important to present some subsystems mathematical models that are involved in WECS based on double fed induction generator (DFIG), see fig. 1.

\subsection{Back to Back (BTB) Model}

The BTB scheme is formed by two shared VSC with a common DC bus. Both can operate as a rectifier or inverter depending on the power flow direction and the operation is complementary. The VSC shown in Fig. 2 is the three-phase diagram with three-wire connected to the AC load represented by a Thevenin equivalent circuit by means a coupling transformer inductance and resistance $\left(\mathrm{L}_{\mathrm{T}}, \mathrm{R}_{\mathrm{T}}\right)$. The DC converter terminal is connected to a shunt capacitance, $\mathrm{C}_{\mathrm{dc}}$. The three-phase AC side VSC voltage balancing equation is:

$$
L_{S} \frac{d \mathbf{I}_{a b c}}{d t}+R_{S} \mathbf{I}_{a b c}+L_{T} \frac{d \mathbf{I}_{a b c}}{d t}+R_{T} \mathbf{I}_{a b c}=\mathbf{V}_{S a b c}-\mathbf{V}_{T a b c}
$$

where $I_{a b c}=\left[\begin{array}{lll}I_{a} & I_{b} & I_{c}\end{array}\right]^{\mathrm{T}} ; V_{\text {Sabc }}=\quad\left[\begin{array}{lll}V_{S a} & V_{S b} & V_{S c}\end{array}\right]^{T}$; $\mathrm{V}_{\mathrm{Tabc}}=\left[\begin{array}{lll}\mathrm{V}_{\mathrm{Ta}} & \mathrm{V}_{\mathrm{Tb}} & \mathrm{V}_{\mathrm{Tc}}\end{array}\right]^{\mathrm{T}}$ are the three phase current, source and terminal voltage vector, respectively. The rms amplitude $\mathrm{V}_{\mathrm{Tm}}=\mathrm{m}_{0} \mathrm{~V}_{\mathrm{dc}}$ is obtained by the PWM modulation index $\left(0<\mathrm{m}_{0}<1\right)$. The frequency $\omega$ and phase angle $\emptyset_{\mathrm{T}}$ are PWM voltage source converter controllable variables.

The DC-side voltage dynamic expression is deduced based on power balance between the AC and DC-side as,

$$
v_{d c}(t) i_{d c}(t)=P(t)-P_{L}(t)
$$

where $\mathrm{P}(\mathrm{t})$ is the instantaneous real power at point of common coupling; $P_{L}(t)$ includes the total power loss; and $P_{d c}=v_{d c} i_{d c}$ is the transferred power from the DC side to the load. The DC current is:

$$
C_{d c} \frac{d v_{d c}}{d t}=i_{d c}-\frac{v_{d c}}{R_{d c}}
$$

both VSCs have the same dynamic model, only one acts as a rectifier and another as inverter.

\subsection{Control Scheme}

The control objectives for the BTB operation are set depending on the application. In this paper for DFIG, we are seeking to maintain the dc voltage at a constant value and the wind system operation with a unity power factor, which means that the reactive power flow towards the grid must be

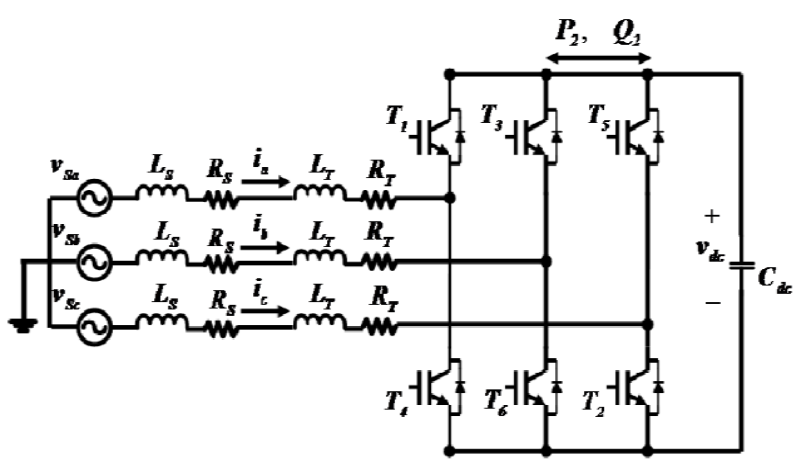

Fig. 2. Voltage source converter model.

zero. The source side converter objective is to keep the dclink voltage constant. The vector control method is used with a reference frame oriented along vector position, enabling independent control of the active and reactive power flowing between the source and the converter [11]. The PWM signals are obtained by current regulated scheme, with $d$-axis current used to manipulate the DC voltage and the $q$-axis current component to regulate the reactive power. The voltage equations in synchronously rotating $\mathrm{dq}-$ axis reference frame are [12]:

$$
\begin{gathered}
v_{c d}=R i_{c d}+L_{c h o k e} \frac{d i_{c d}}{d t}-\omega_{e} L_{c h o k e} i_{c q}+v_{c d 1} \\
v_{c q}=R i_{c q}+L_{c h o k e} \frac{d i_{c q}}{d t}+\omega_{e} L_{c h o k e} i_{c d}+v_{c q 1}
\end{gathered}
$$

The grid voltage angular position is calculated as

$$
\theta_{e}=\int \omega_{e} d t=\tan ^{-1} \frac{v_{c \beta}}{v_{c \alpha}}
$$

where $v_{\mathrm{c} \alpha}$ and $v_{\mathrm{c} \beta}$ are the converter source side voltage components in stationary frame. The $d$-axis of the reference frame is aligned with the grid voltage angular position $\theta_{\mathrm{e}}$. Since the grid voltage amplitude is constant, $v_{\text {cd }}$ is constant and $v_{\mathrm{cd}}=0$. The active and reactive power will be proportional to $i_{\mathrm{cd}}$ and $i_{\mathrm{cq}}$, respectively. Thus, the control scheme utilizes a decoupled currents, $i_{\mathrm{cd}}$ and $i_{\mathrm{cq}}$. The component $i_{\mathrm{cd}}$ is derived from the DC voltage error through a PI controller. $i_{\mathrm{cq}}$ determines the displacement factor in the inductors supplyside. The reference values for the grid-side converter $v_{\mathrm{d} 1}^{*}$ and $v_{\mathrm{q} 1}^{*}$ are established with a PI controller.

$$
\begin{gathered}
v_{c d}^{*}=-v_{c d}^{\prime}+\left(\omega_{e} L_{c h o k e} i_{c q}+v_{d}\right) \\
v_{c q}^{*}=-v_{c q}^{\prime}-\left(\omega_{e} L_{c h o k e} i_{c d}\right)
\end{gathered}
$$

The rotor-side converter provides the excitation for the rotor. With this VSC is possible to control the torque, hence the Induction Generator (IG) speed and also the power factor at the stator terminals. The rotor-side converter provides a varying excitation frequency depending on the wind speed conditions. The IG is controlled in a synchronously rotating $d q 0$, with the $d$-axis oriented along the stator-flux vector position. This is called stator-flux orientation vector control. In this way, a decoupled control between the electrical torque and the rotor excitation current is obtained [11]. Consequently, the active power and reactive power are controlled independently from each other. To describe the control scheme, the induction machine model is introduced. 
Using the motor convention in a static stator-oriented reference frame without saturation, the voltage vector equations are [12],

$$
\begin{gathered}
\vec{v}_{s}=R_{s} \vec{i}_{s}+\frac{d \vec{\psi}_{s}}{d t} \\
\vec{v}_{r}=R_{r} \vec{i}_{r}+\frac{d \vec{\psi}_{r}}{d t}-j \omega \vec{\psi}_{r}
\end{gathered}
$$

where $\vec{v}_{S}$ is the stator voltage imposed by the grid. The rotor voltage $\vec{v}_{r}$ is controlled by the rotor-side converter and used to perform generator control. Under stator-flux orientation, in $d q$ axis component form, the stator flux equations are:

$$
\left\{\begin{array}{l}
\psi_{s d}=L_{s} i_{s d}+L_{m} i_{r d} \\
\psi_{s q}=0
\end{array}\right.
$$

defining leakage factor $\sigma=1-L_{\mathrm{m}}^{2} / L_{\mathrm{s}} L_{\mathrm{r}}$ and equivalent inductance as $L_{0}=L_{\mathrm{m}}^{2} / L_{\mathrm{s}}$, the rotor voltage and flux equations are (scaled to be numerically equal to the ac per-phase values):

$$
\begin{aligned}
& \left\{\begin{array}{l}
v_{r d}=R_{r} i_{r d}+\sigma L_{r} \frac{d i_{r d}}{d t}-\omega_{s l i p} \sigma L_{r} i_{r q} \\
v_{r q}=R_{r} i_{r q}+\sigma L_{r} \frac{d i_{r q}}{d t}+\omega_{s l i p}\left(L_{0} i_{m s}+\sigma L_{r} i_{r d}\right)
\end{array}\right. \\
& \left\{\begin{array}{l}
\psi_{r d}=\frac{L_{m}^{2}}{L_{s}} i_{m s}+\sigma L_{r} i_{r d} \\
\psi_{r q}=\sigma L_{r} i_{r q}
\end{array}\right.
\end{aligned}
$$

where the slip angular speed is $\omega_{\text {slip }}=\omega_{\mathrm{s}}-\omega_{\mathrm{r}}$

$$
\left\{\begin{array}{l}
v_{r d}^{\prime}=R_{r} i_{r d}+\sigma L_{r} \frac{d i_{r d}}{d t} \\
v_{r q}^{\prime}=R_{r} i_{r q}+\sigma L_{r} \frac{d i_{r q}}{d t}
\end{array}\right.
$$

To ensure good tracking of the rotor $d q$ - axis currents, compensation terms are added to $v_{\text {rd }}^{\prime}$ and $v_{\text {rq }}^{\prime}$ to obtained the reference voltages $v_{\text {rd }}^{*}$ and $v_{\text {rq }}^{*}$ according to

$$
\left\{\begin{array}{l}
v_{r d}^{*}=v_{r d}^{\prime}-\omega_{s l i p} \sigma L_{r} i_{r q} \\
v_{r q}^{*}=v_{r q r}^{\prime}+\omega_{s l i p}\left(L_{m} i_{m s}+\sigma L_{r} i_{r d}\right)
\end{array}\right.
$$

The electromagnetic torque is

$$
T_{e}=-\frac{3}{2} p \operatorname{Im}\left\{\vec{\psi}_{s} \vec{i}_{r}^{*}\right\}=-\frac{3}{2} p L_{0} i_{m s} i_{r q}
$$

where $i^{*}$ rq

$$
i_{r q}^{*}=-\frac{2 T_{e}^{*}}{3 p L_{0} i_{m s}}=-\frac{2 T_{e}^{*}}{3 p \psi_{s}}
$$

The reference values for the rotor-side converter $v_{\mathrm{rd}}^{*}$ and $v_{\mathrm{rq}}^{*}$ are established with a PI controller, respectively. Also a PI controller for $i_{\text {rq }}^{*}$ is needed. One important issue is how we can select the best PI parameters for the seven linear controllers, three for grid side and others for rotor side, thus fourteen parameters are required. Usually, this procedure is carried out based on linear analysis.

\section{RESULTS}

The proposed can be achieved adding a B-spline neural network to update all gains in only five PI controllers, rotor and source sides. Thus, $k_{\mathrm{p}}$ and $k_{\mathrm{i}}$ are updated from a B-spline neural network at every sampled time. With this purpose, ten BSNN are assembled in the control scheme. The B-spline neural networks are a particular case of neural networks that allow to control and model systems adaptively, with the option of carrying out such tasks on-line, and taking into account the power grid non-linearity. Through BSNN there is the possibility to bound the input space by the basis functions definition. Therefore, not all the weights have to be calculated each sample time, thus reducing the computational effort and time.

The BSNN's output can be described by [13],

$$
y=\mathbf{a}^{T} \mathbf{w}
$$

where

$$
\begin{aligned}
w & =\left[\begin{array}{lll}
w_{1} & w_{2} & \ldots w_{\rho}
\end{array}\right]^{T} \\
a & =\left[\begin{array}{lll}
a_{1} & a_{2} & \ldots a_{\rho}
\end{array}\right]^{T}
\end{aligned}
$$

where $w_{\mathrm{i}}$ and $a_{\mathrm{i}}$ are the $i$-th weight and the $i$-th BSNN basis function output, respectively; $\rho$ is the number of weighting factors.

In this paper, it is proposed that $k_{\mathrm{p}}$ and $k_{\mathrm{i}}$ can be adapted through one B-spline neural network, respectively, for each voltage source converter. The error signals are the same of PI controllers. Then the dynamic control parameters for back to back system can be described as follows:

$$
K_{x}=N N_{m}\left(e_{x}, w_{\rho}\right)
$$

where $N M_{\mathrm{m}}$ denotes the B-spline network which is used to calculate $k_{\mathrm{p}}$ and $k_{\mathrm{i}} ; w_{\rho}$ is the corresponding weighting factor; $m=1,2,3$ number of PI controllers. Fig. 3 depicts a scheme of the proposed B-spline neural network.

The appropriate design requires the following a-priori information: the bounded values of $e_{x}$, the size, shape, and overlap definition of the basis function. Likewise, with this information the BSNN estimates the optimal weights' value. The neural network adaptive parameters, equations (18)-(20), are created by univariate basis functions of order 3 , considering that $e_{x}$ are bounded within $[-12,12]$. In this paper, the BSNN is trained on-line using the following error

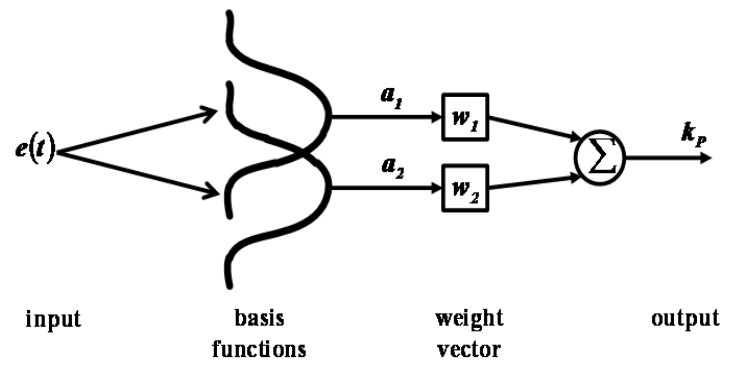

Fig. 3. Proposed BSNN for adapting control parameters. 
correction instantaneous learning rule [13]:

$$
w_{i}(t)=w_{i}(t-1)+\frac{\eta e_{i}(t)}{\|\mathbf{a}(t)\|_{2}^{2}} a_{i}(t)
$$

where $\eta$ is the learning rate and $e_{i}(t)$ is the instantaneous output error. Respect to the learning rate, it takes as initial value one point within the interval $[0,2]$ due to stability purposes. This value is adjusted by trial-and-error. If $\eta$ is set close to 0 , the training becomes slow. On the contrary, if it is large, oscillations may occur. In this application, it settles down in 0.051 for $k_{\mathrm{p}}$, and 0.0016 for $k_{\mathrm{i}}$. The BSNN training process is carried out continuously on-line, while the weights' values are updated.

\subsection{Electrical Grid}

In order to demonstrate the feasibility of this proposition, an electrical grid with a WECS system is employed. MatlabSimulink are used for simulation, the proposed tuning performance is exhibited. The step time integration was defined variable due the simulations present slow and fast disturbances. To analyze the results, simulations are developed under different scenarios with PI controllers tuned by BSNN (dynamic parameters), ANNPI, and fixed parameters (static), FXPI. Some operating conditions are taken into account. To examine the results three situations are presented. The systems data are: for the source $120 \mathrm{KV}, 60$ $\mathrm{Hz}$ and the WECS is at $575 \mathrm{~V}, 9 \mathrm{MVA}$; in terminals a 500 MW load is connected. Two transmission lines at $25 \mathrm{KV}$ are connected to both systems. The first condition exhibits some control parameters training. In Fig. 4 four PI parameters are shown $k_{\mathrm{p}}$ for DC link control scheme; $k_{\mathrm{p}}$ and $k_{\mathrm{i}}$ for $v_{\mathrm{d}}$ reference value in current regulator grid side; $k_{\mathrm{p}}$ for reactive power controller in rotor side converter; finally, $k_{\mathrm{i}}$ for DC bus control is presented, see Fig. 5. In these cases the parameters have a typical initial condition for this regulator purpose, after that, each one attain the better value in grid operation condition. In this case a 10 percent load at WECS terminals was increased.

Once the control parameters are first tuning the updating procedure goes on based on learning on-line rule. The second situation is a slow perturbation when the wind speed changes from 8 to $14 \mathrm{~m} / \mathrm{s}$ in 6 seconds. After that, the parameters are retuned to reach better performance in this new operation condition. The Fig. 6 shows that the dynamic behavior of the proposed scheme is better than that of the conventional PI with fixed parameters in DC voltage when the system is subject to wind speed change, similar transient characteristics in reactive power exchange is observed, see Fig. 7.

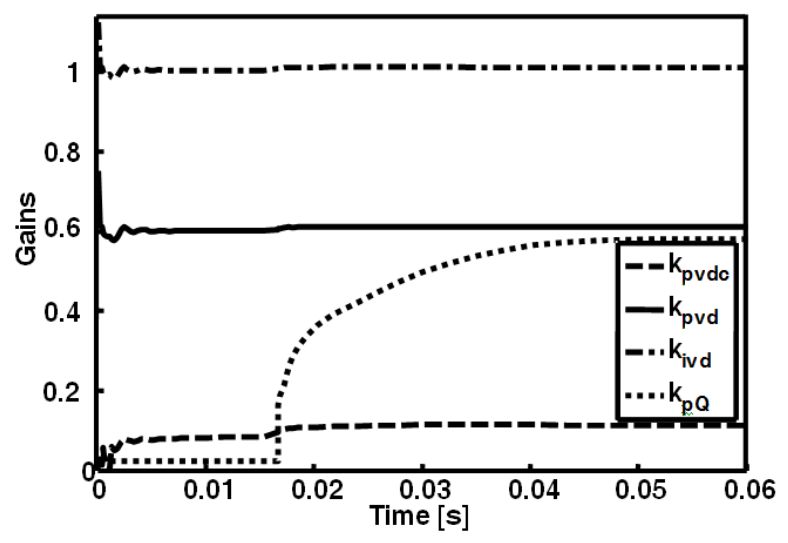

Fig. 4. Gains in controllers for $v_{d c}, v_{d}$ and $Q$.
The third case validates the appropriate system evolution when the load is increased in WECS terminals in 200 percent, from $500 \mathrm{MW}$ to $1500 \mathrm{MW}$. The Fig. 8 exhibits the DC voltage evolution; about 0.02 seconds to achieve the stationary state are needed, otherwise, for FXPI the overshoot and settling time are larger. Active powers in WECS terminals and the electrical grid middle are presented in the Figs. 9-10. The results showed are in accordance with the case 2 . In the Fig. 10, one can appreciate that the source-side instead receive 6.2 MW, only obtain 5.2 MW due one load are added. As shown in the Figs. 6-9, the adaptive controller parameters performance can decrease the oscillations amplitude and

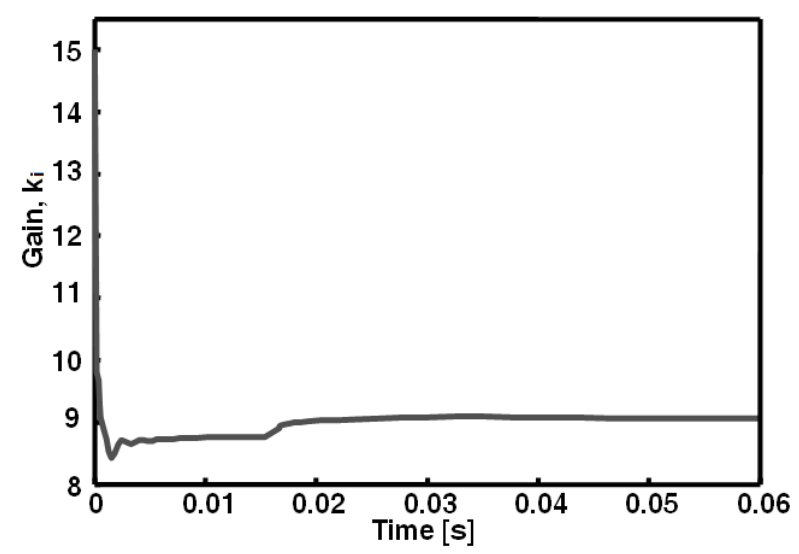

Fig. 5. First updating for $\mathbf{k} \_\mathbf{i}$ in controller 1 .

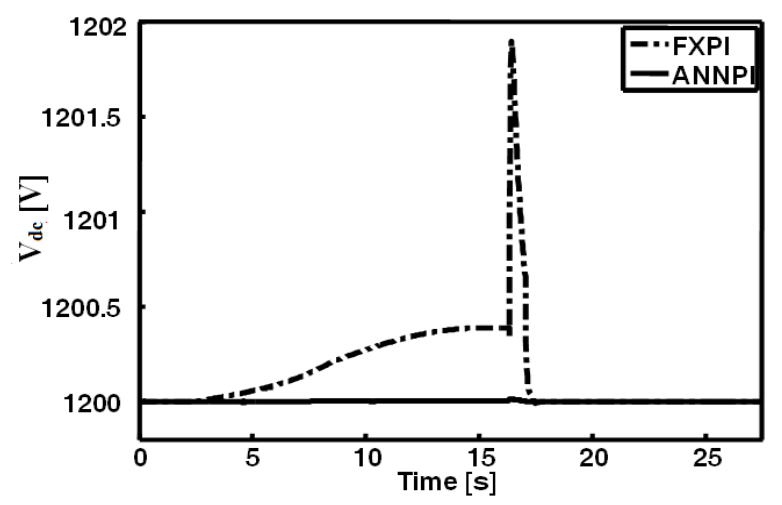

Fig. 6. DC link voltage performance, case 2.

transient time under different operating conditions, respect to the behavior with fixed control parameters. Similar performance is exhibited with other variables in the cases 2 and 3 for instance $v_{\mathrm{dc}}, \mathrm{Q}$ and, $i_{\mathrm{d}}$. In this paper, we integrate only five adaptive parameters. The PI controller parameters in steady state after case 3 are: grid side $\left(v_{\mathrm{dc}}, v_{\mathrm{d}}, v_{\mathrm{q}}\right)$ [0.0897, $8.8267,0.5978,1.0011,1.2542,2.0286]$; rotor side $\left(i_{\mathrm{rd}}, i_{\mathrm{rq}}\right)$ $[0.7045,56.3987,2.0417,47.7654], k_{\mathrm{p}}$ and $k_{\mathrm{i}}$, respectively. The parameters are updated every sampled time by BSNN. It is clear that the tuning scheme adapts by itself for different operation conditions, thus guarantying the satisfactory electric net operation. In order to attain such purposes a B-spline neural wetwork-based control is proposed. We can see from the simulation results that the system with the proposed control method has a stable operation at various load conditions. 


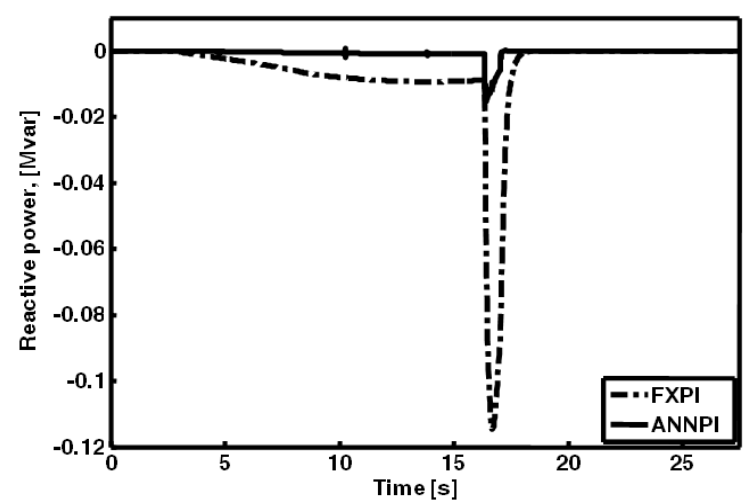

Fig. 7. Reactive power exchange, case 2

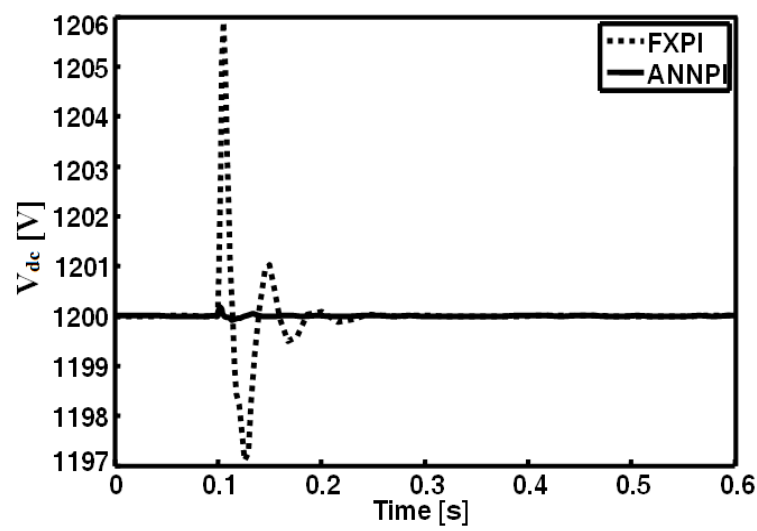

Fig. 8. DC link voltage performance, case 3.

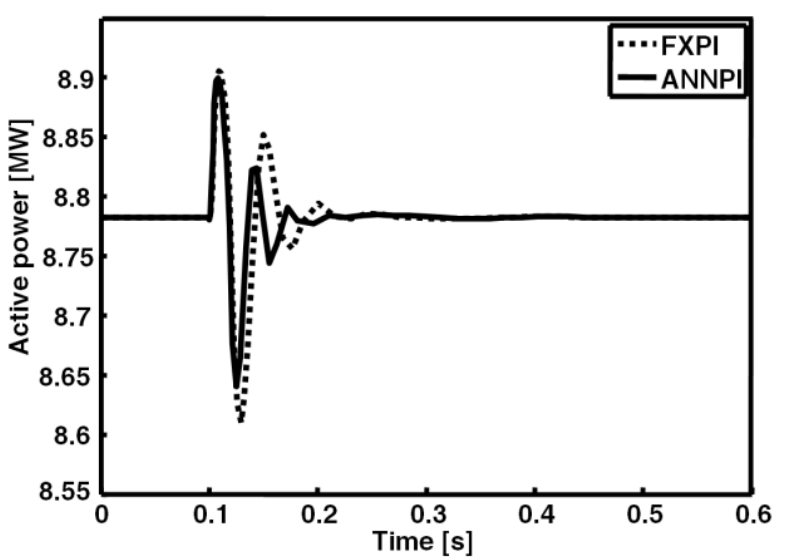

Fig. 9. Active power in WECS terminals, case 3.

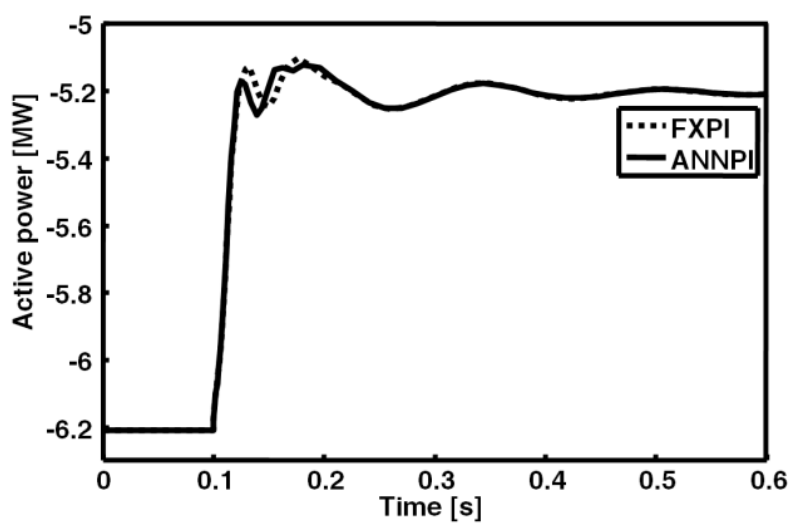

Fig. 10. Active power flow between source and WECS sides connected by two lines, case 3 .

\section{CONCLUSIONS}

The aim of this paper was to show the performance of adaptive PI parameters as a mean to tune linear controllers in WECS system. In order to attain such purposes a B-spline neural network-based is proposed. With this neural adaptive scheme, the possibility to implement the on-line updating parameters is potential due to it has learning ability and adaptability, robustness, simple algorithm and fast calculations This is desirable for practical hardware implementation in power stations. Unlike the conventional technique, the B-spline $\mathrm{NN}$ exhibits an adaptive behavior since the weights can be adapted on-line responding to inputs and error values as they arise. Also, it can take into account nonlinearities, un-modeled dynamics, and un-measurable noise. Simulations on electrical grid under different disturbances and operating conditions, demonstrate the effectiveness and robustness of the proposed strategy.

\section{ACKNOWLEDGMENTS}

This project has been funded by the CONACyT-Mexico grant CB-169062 and also it has been partially funded by PROMEP: Redes Temáticas de Colaboración under the project titled: Fuentes de Energías Alternas.

\section{REFERENCES}

[1] Hoa M. Nguyen, D. Subbaram Naidu, "Advanced Control Strategies for Wind Energy Systems: An Overview", Proc. IEEE PES Power Systems Conference\& Exposition (PSCE), 2011.

[2] S. Niu, K.T. Chau, J.Z. Jiang, and C. Liu, "Design and control of a new double-stator cup-rotor permanentmagnet machine for wind power generation," IEEE Trans. Magnetics, vol. 43, No. 6, pp. 2501-2503, 2007.

[3] Yi Wang, Lie $\mathrm{Xu}$, "Coordinated Control of DFIG and FSIG-Based Wind Farms Under Unbalanced Grid Conditions", IEEE Trans. Power Delivery, vol. 25, No. 1, pp. 367-377, 2010.

[4] F. M. Hughes, O. Anaya-Lara, N. Jenkins, and G. Strbac, "Control of DFIG-based wind generation for power network support," IEEE Trans. Power Systems, vol. 20, No. 4, pp. 1958-1966, 2005.

[5] Mostafa Soliman, O. P. Malik, David T. Westwick, "Multiple Model Predictive Control for Wind Turbines With Doubly Fed Induction Generators", IEEE Trans. Sustainable Energy, vol. 2, No. 3, pp. 215- 225, 2011

[6] Janeth Alcalá, Víctor Cárdenas, Emanuel Rosas Ciro Núñez, "Control system design for bi-directional power transfer in Single-Phase Back-to-Back converter based on the linear operating region", Proc. IEEE Applied Power Electronics Conference and Exposition (APEC), pp. 1651- 1658, 2010.

[7] Van-Tung Phan, Hong-Hee Lee, "Performance Enhancement of Stand-Alone DFIG Systems With Control of Rotor and Load Side Converters Using Resonant Controllers", IEEE Trans. Industry Applications, vol. 48, No. 1, pp. 199 - 210, 2012.

[8] J. Hu, H. Nian, B. Hu, Y. He, and Z. Q. Zhu, "Direct active and reactive power regulation of DFIG using sliding-mode control approach," IEEE Trans. Energy Conversion, vol. 25, No. 4, pp. 1028-1039, 2010.

[9] H. Camblong, I. M. de Alegria, M. Rodriguez, and G. Abad, "Experimental evaluation of wind turbines 
maximum power point tracking controllers," Energy Convers. Manage., vol. 47, pp. 2846-2858, 2006.

[10] M. Sedighizadeh, D. Arzaghi-Harris, and M. Kalantar, "Adaptive PID control of wind energy conversion systems using RASP1 mother wavelet basis function networks," Proc. IEEE Conference in TENCON, vol. C, pp. $524-527,2004$.

[11] R. Pena, J.C.J.C Clare, G.M. Asher, "Doubly fed induction generator using back-to-back PWM converters and its application to variable-speed wind-energy generation", IEE Proc. Electric Power Applications, vol.143, No. 3, pp. 231-241, 1996.

[12] B. Wu, Y. Lang, N. Zargari, S. Kouro, "Power Conversion and Control of Wind Energy Systems", Jonh Wiley and Sons, pp. 25-47, 2011.

[13] Brown, and C. Harris, "Neurofuzzy Adaptive Modelling and Control," Prentice Hall, 1994.

[14] R. C. Baker and B. Charlie, "Nonlinear unstable systems," International Journal of Control, vol. 23, no. 4, pp. 123-145, May 1989.

[15] G.-D. Hong, "Linear controllable systems," Nature, vol. 135, no. 5, pp. 18-27, July 1990.

[16] K. S. Hong and C. S. Kim, "Linear stable sys-tems," IEEE Trans. on Automatic Control, vol. 33, no. 3, pp. 1234-1245, December 1993.

[17] Z. Shiler, S. Filter, and S. Dubowski, "Time op-timal paths and acceleration lines of robotic manipulators," Proc. of the 26th Conf. Decision and Control, pp. 98-99, 1987.

[18] M. Young, The Technical Writer's Handbook, Mill Valley, Seoul, 1989.

[19] W.M. Newmann, R.F. Sproull, Principles of Interactive Computer Graphics, Mc-Graw-Hill, Inc., 1979.

[20] N. Yadaiah, B.L. Deekshatulu, L. Sivakumar, V.S.H. Rao, Neural network algorithm for parameter identification of dynamical systems involving time delays, Appl. Soft Comput. 7 (3) (2007) 1084-1091

\section{AUTHOR'S PROFILE}

Ruben Tapia Olvera obtained his BS in Electrical Engineering from Instituto Tecnológico de Pachuca, México in 1999; M.Sc., and Ph. D., in Electrical Engineering from CINVESTAV Guadalajara, México in 2002 and 2006, respectively. He is currently full time professor at the Universidad Politécnica de Tulancingo. His primary area of interest is on the modeling and control of FACTS devices with computational intelligence techniques.

Abel Garcia-Barrientos was born in Tenancingo, Tlaxcala, Mexico, in 1979. He received the Licenciatura degree in Electronics from the Autonomous University of Puebla, Mexico, in 2000, and the M.Sc. and Ph.D. degree in Electronics from the National Institute for Astrophysics, Optics, and Electronics (INAOE), Tonantzintla, Puebla, in 2003 and 2006, respectively. In 2007 he joined as a researcher at the Mechatronics Department at the Polytechnic University of Pachuca, Mexico. In 2009 he was a Post-Doctoral Fellow at the Micro- and Nano-Systems Laboratory at the McMaster University, Ontario, Canada. Dr. Garcia-Barrientos joined the Advanced Materials and Device Analysis group of Institute for Microelectronics at the Technische Universität Wien, in 2010. In 2013, he joined as a Assistant Professor at the Research Center for Information Technologies and Systems, Autonomous University of Hidalgo State (UAEH), Hidalgo, Mexico. His scientific interests include device simulation, semiconductor device modeling, high-frequency electronics, and robotics.

Omar Jacobo Santos-Sanchez completed his undergraduate studies at the Instituto Tecnologico de Minatitlan,Veracruz from 1992-1997. He received the Master and Doctor Degrees from the Department of Automatic Control, CINVESTAVIPN in 2000 and 2006, respectively. Since 2001, Dr. SantosSanchez is a full-time researcher at the Autonomous University of the State of Hidalgo, Mexico. His areas of interest are: optimal control of systems with delays, stability analysis and control systems with nonlinear delays. Since 2008, he has been a member of the National System of Researchers-CONACyT. 